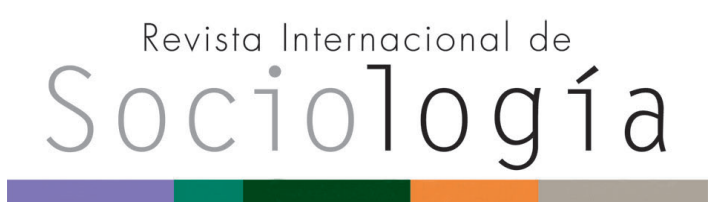

Revista Internacional de Sociología RIS vol. 74 (3), e037, julio-septiembre, 2016, ISSN-L:0034-9712 doi: http://dx.doi.org/10.3989/ris.2016.74.3.037

\section{A CRITICAL REVIEW OF DUNBAR'S SOCIAL BRAIN HYPOTHESIS}

\author{
Cristina Acedo-Carmona \\ University of the Balearic Islands \\ cristina.acedo@uib.es \\ ANTONI GomiLA \\ University of the Balearic Islands \\ toni.gomila@uib.es
}

Cómo citar este artículo / Citation: Acedo-Carmona, C. and A. Gomila. 2016. "A critical review of Dunbar's social brain hypothesis". Revista Internacional de Sociología 74(3): e037. doi: http://dx.doi.org/10.3989/ris.2016.74.3.037

\begin{abstract}
Dunbar's social brain hypothesis constitutes an influential position among those that relate the evolution of human cognition and sociality. In this work, we first present the essentials of the theory and discuss the paleoanthropological and social evidence claimed to support it. We also point out its shortcomings, which have to do with the general strategy of finding linear relations among different traits, the lack of attention to the mental capacities that make human social life possible, and the diversity of social relations and structures that take place. We put forward our way of complementing Dunbar's approach by focusing on the role of trust in cementing society and explaining diversity.
\end{abstract}

\section{KEYWORDS}

Cognition; Evolution; Group; Neocortex; Sociality.

\section{UNA REVISIÓN CRÍTICA DE LA HIPÓTESIS DEL CEREBRO SOCIAL DE DUNBAR}

Copyright: @ 2016 CSIC. Este es un artículo de acceso abierto distribuido bajo los términos de la licencia Creative Commons Attribution (CC BY) España 3.0.

Received: 18/09/2014. Accepted: 01/07/2015. Published on line: 22/08/2016

\section{Resumen}

La hipótesis del cerebro social de Dunbar constituye una posición influyente entre aquellas que relacionan la evolución de la cognición y la socialidad humanas. En este trabajo, tras presentar los puntos esenciales de su teoría, discutimos las evidencias paleo-antropológicas y sociales en las que se sustenta. También señalamos algunas limitaciones. Tales limitaciones tienen que ver con la estrategia general de buscar relaciones lineales entre diferentes rasgos, la insuficiente atención a las capacidades mentales que hacen posible la vida social humana, y a la diversidad de las estructuras sociales efectivas. Presentamos nuestra forma de complementar el enfoque de Dunbar al centrarnos en el papel que juega la confianza como cemento de la sociedad y para explicar la diversidad

\section{Palabras Clave}

Cognición; Evolución; Grupo; Neocórtex; Socialidad. 


\section{INTRODUCTION}

Following Humphrey's suggestion in "The social function of the intellect" (Humphrey 1976), diverse theoretical proposals have developed the hypothesis of the existence of a crucial relation between human cognition and sociality from an evolutionary point of view. For example, the Machiavellian Intelligence Hypothesis (Byrne and Whiten 1988) or the Vygotskian Intelligence Hypothesis (Moll and Tomasello 2007) coincide in trying to explain the existence of certain cognitive capacities in humans - such as to detect lies or to establish cooperative plans - in terms of their evolutionary function, as adaptive solutions to the selective pressures derived from the increasing complexity characterizing social life throughout the Hominin lineage. It is important to note the dual explanatory link between cognition and sociality involved in these proposals: on the one hand, certain cognitive abilities are required to exhibit relevant social behaviors; and on the other hand, these cognitive abilities are thought to have evolved because the social behaviors they enabled were adaptive. An evolutionary account of the mind involves an account of sociality, and vice versa.

This dual explanatory link turns out to be even more intricate when we consider one of the most influential programs that relates the cognitive and social evolution of our species: Dunbar's Social Brain Hypothesis (SBH) (Dunbar 2010; Dunbar and Shultz 2007; Shultz and Dunbar 2007; Dunbar 1998; Dunbar 1992).The hypothesis states that our brain is an adaptation to our social life, so instead of singling out the cognitive functions required for our kind of social life, Dunbar focuses on the brain that supports those functions. The idea consists of indicating the interdependence between the type of social life that characterizes humans and the neural requisites necessary to sustain the mental functions that make this type of sociality possible. It is also assumed that this brain evolved -by basically increasing its relative size- because of the adaptive advantages derived from the social organization it made possible. It is assumed that this is the right level of explanation, overlooking the fact that the same brain is involved in a diversity of human societies. In other words, social diversity is kept out of the picture; it is just assumed that it must be constrained by the evolved human social brain.

Undoubtedly, there are advantages in the formulation of the evolutionary hypothesis in terms of an increase in brain size instead of particular cognitive functions. From the point of view of the hominization process, the increase in relative brain size is an indisputable fact. However, from an evolutionary point of view, this increase also involved higher metabolic costs, such as higher energy consumption, risk of overheating, or greater demands for the heart to pump blood. The SBH stresses the adaptive advantages of this brain enlargement in terms of the be- nefits of complex social life, in the sense that brains had to be larger than the biological costs. A diversity of evidence is brought to support it. Thus, for instance, comparative studies of several species in different evolutionary conditions are required to establish both homologies within our own lineage and convergences with other taxa to consider whether or not a relation between larger brains and social complexity can be established. Similarly, paleontological and anthropological data about our ancestors can help establish universal constraints in social complexity among the diversity of human cultures. In particular, the $\mathrm{SBH}$ predicts that the human brain sets a limit on the scope and quality of human social relationships.

In this work, we review these different lines of evidence to assess in which way and to which extent Dunbar's SBH is well supported. In our opinion, the weak points of this proposal come from the need to go beyond a too simple initial proposal based on a correlational methodology, which requires seeking simple linear relations, and overlooks the possibility of complex interactions among multiple factors. These weaknesses are evident precisely in the ambiguity indicated between the assumed original social configuration and his claim that it still holds through the diversity of human societies. An articulated view of the cognitive mechanisms needed for a human social life in its diversity is also required, just as attention to the diversity of social relations is also due. In our view, it is in this way that human universals can be found, rather than in terms of maximum size of social groups, as Dunbar contends. In fact, it seems that in his more recent work, which focuses on trust-based groups, Dunbar is currently developing the SBH precisely in this direction. We will propose how trust can provide the key to better articulate his position.

\section{THE RELATION BETWEEN RELATIVE BRAIN SIZE AND GROUP SIZE}

One of the most clear anatomical features of the hominization process is the increase in brain size relative to body size; a process that started with the primates. In primates, it seems that the relative increase in brain size takes place especially in the telencephalon: the neocortex occupies between $50 \%$ and $80 \%$ of the entire cerebral volume depending on the species. A great number of authors have emphasized the problems of survival in a new ecological environment as the key to such a process. The ecological hypothesis $(\mathrm{EH})$ posits that the selective pressures that our ancestors had to confront, given the available resources in the savanna, and the absence of "weapons" (claws, canine teeth, etc.) and brute force favored a bigger brain, assuming that intelligence depends on (relative) brain size. The SBH, on the contrary, views this increase primarily as a way of making it possible to live in larger groups, which is thought to be advantageous in the new environment. Therefore, both theories relate en- 
vironmental pressure and bigger brains; the difference between the SBH and the EH lies in the fact that the EH views such a brain increase as an individual strategy, whereas the SBH views it as allowing a more complex social organization, which in turn, gave rise to new demands. SBH, though, is neutral on whether the new social conditions that come with bigger groups favor more cooperation ("Vygotskian intelligence") or competition ("Machiavellian intelligence"), because it is group size per se, and not the kind of relationships within the group, that is related to such an increase in relative brain size.

As evidence against the $\mathrm{EH}$, Dunbar quotes the McNab and Eisenberg (1989) study, which showed that relative brain size in mammals correlates more clearly with their daily routines than with their metabolic ratio (the amount of energy liberated per unit of time). Dunbar $(1998,2003)$ also examined a possible correlation in primates between the increase in relative volume of the neocortex (neocortex volume compared to total brain volume) and ecological indicators such as the proportion of consumed fruit in diet and the foraging style (Fig. 1) or the length of daily displacements, but found none.

On the contrary, the relative size of the neocortex correlates with group size in anthropoids (Kudo and Dunbar 2001; Dunbar 1992; 1995) as predicted by SBH (Fig. 2). However, when the same variables were compared in other mammals, such as bats, artiodactyls ungulates and carnivores, and 135 species of birds, the pattern turned out to be more nuanced: beyond group size, it is the type of relationships among group members that matters most. Thus, species organized in stable couples have bigger relative brains than those living a solitary life or in multi-male groups (Shultz and Dunbar 2007).
Therefore, the evidence suggests that group size is not all there is to bigger brains: the complexity of the social relationships involved also seems to play a role. Support for the SBH is only modest. An analysis of the characteristics of social life, beyond group size, seems to be in order. In recent work, Dunbar has become aware of this, as we will see in the Section "Enlarged neocortex and social life".

\section{Costs AND BENEFITS OF LIFE IN COMPLEX GROUPS}

Even in the case of primates, where the correlation between bigger group size and higher brain ratio holds, the question of the costs and benefits of social life needs to be addressed. Group size might be a mere by-product of developing bigger brains for some other reason. Hill and Dunbar (1998), Dunbar (1988) and Van Schaik (1983) found support for the idea that the increase in the brain's ratio is the key to bigger groups, which would be advantageous in the new ecological conditions of our ancestors. More specifically, Dunbar (2003) argued that bigger groups cannot be a by-product of bigger brains because of the costs of living in society: group living is so demanding that it constitutes an evolutionary pressure per se, so that if advantages were not superior to costs, the group would disperse. In his opinion, the advantages of group living include diminishing predation risks, improving territory defense, and sharing the breeding of progeny. As for the costs of living in bigger groups, they involve competition for scarce resources and sexual partners, conflicts among the group members, and, in general, the need to solve coordination problems. Therefore, the larger the group, the higher the costs of keeping the group together, both in terms of time spent and behaviors addressed to avoid conflicts.

Figure 1.

Relative neocortex size in the anthropoid primates compared to (a) percentage of fruit in diet and (b) types of extractive foraging. In none of the two cases a correlation is found (taken from Dunbar 1998, p.183).

(a)

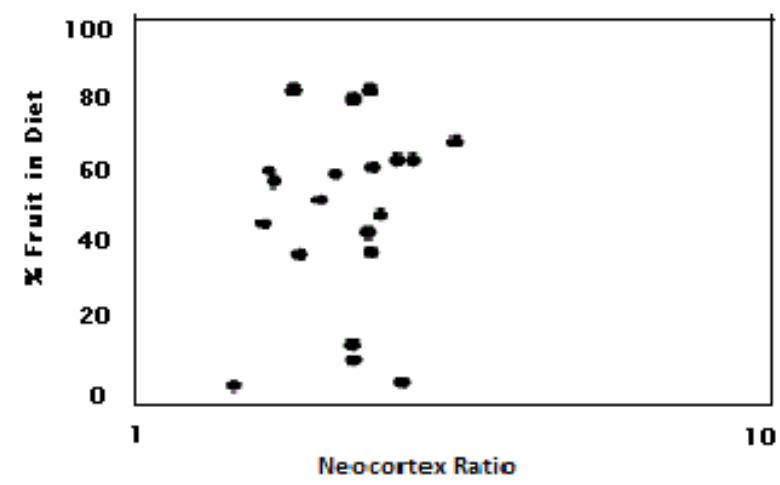

(b)

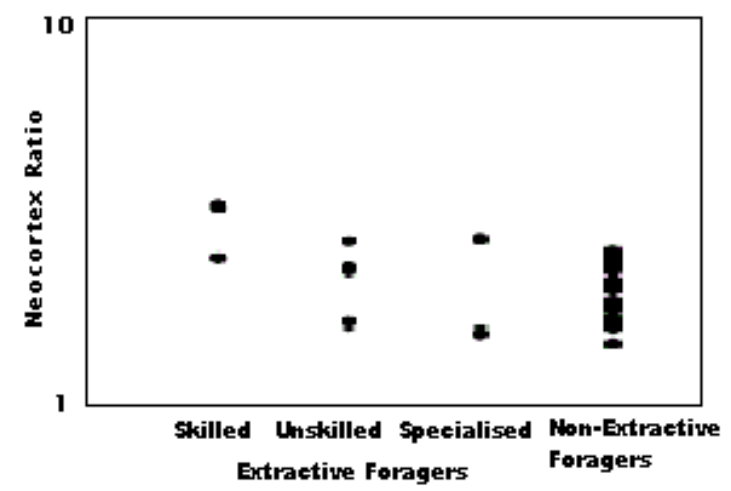


Figure 2.

Correlation between the average size of grooming clique compared to neocortex average ratio for primates and anthropoid monkeys such as L.catta, L.fulvus, Propithecus, Indri, S.sciureus, C.apella, C.torquatus, A.geoffroyi, A.fusciceps, P.badius, P.entellus, P.pileata, P.johnii, C.campbelli, C.diana, C.aethiops, C.mitis, E.patas, M.mulatta, M.fuscata, M.arctoides, M.sylvana, M.radiata, P.anubis, P.ursinus, P.cynocephauls, P.hamadryas, T.gelada, P.troglodytes, P.paniscus(Dunbar 1998, p. 186).

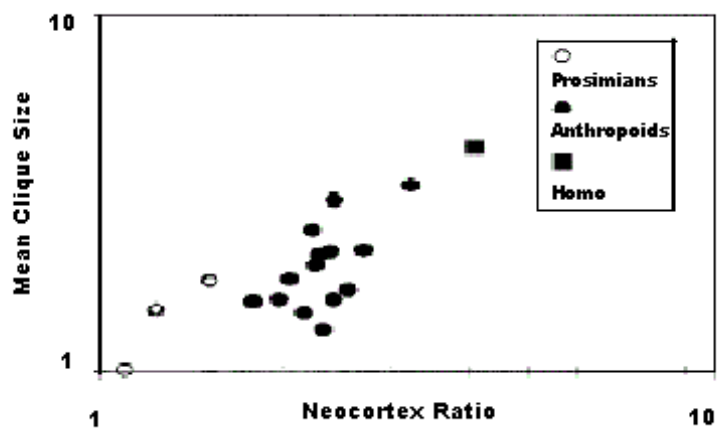

From this point of view, Dunbar (1991) describes the important role of mutual grooming to create ties and to maintain group cohesion in primates. This social activity cannot exceed approximately $20 \%$ of daily time so that other vital activities can be attended to, although the estimation might change among species depending on their different life patterns, habits, social system, predatory pressure, habitat resources, and others. No further precision is provided in this regard.

However, Lehmann, Korstjens, and Dunbar (2007) did not find a correlation between group size and mutual grooming in primates: at a certain level, grooming cannot be the only way of maintaining cohesion. In addition to mutual grooming, other activities, such as games, courtship and mating, agonistic interactions, and territorial behavior, also play a role in maintaining social cohesion (Dunbar 1991). All these activities require a great investment of time and effort, as well as specific cognitive capacities, such as remembering who groomed whom before, with whom one fought, who is allied with whom, and who helps whom in case of conflict. For this reason, instability and group division are to be expected when time to invest and cognitive abilities needed to maintain social ties exceed certain limits.

Dunbar's argument can now be formulated this way: brains evolved for social life because group size depends on the cognitive resources and the time available to keep the group together. From this point of view, a further increase in relative neocortex size in the Hominin lineage, and the superior cognitive abilities that followed, made it possible to preserve cohesion more effectively in the available time, thereby allowing bigger groups.
Nevertheless, this evidence is not enough to support the $\mathrm{SBH}$ idea that an increase in group size leads to the increase in relative brain size, particularly the neocortex. For the SBH, the benefits of increased social activity put a premium on an increase in neocortex volume because superior cognitive skills are needed as a more efficient way to maintain social cohesion, manage bigger groups, and expand the lineage. However, the SBH falls short when attempting to provide a causal explanation of the process: we are not given a clue as to its starting point, nor a reason why other species, which might have also benefited from a complex social life, failed to do so. The SBH is also deficient as a functional account: living in groups as large as human ones can be achieved without following the "bigger brains" strategy - as long as the relationships among members are kept simple. Therefore, the previous critical remark also applies here: what really matters in this process is not so much group size per se as social relations and social structure, since the cognitive way of maintaining social cohesion, in fact, concerns the type of relationships among group members that it makes possible. In bigger groups, hierarchies and coalitions, family structure, and social roles become more complex, giving rise to new forms of social cohesion.

\section{ENLARGED NEOCORTEX AND SOCIAL LIFE}

In recent years, Dunbar has increasingly recognized that the question of the type of social relationships deserves greater attention. An effort in this direction is the work of Shultz and Dunbar (2007): they focus on the connection between relative brain size and type of social relationships by analyzing the different relationships among individuals within the group. Their hypothesis contends that different types of social relationships involve different cognitive demands, which in turn will require different relative brain sizes. They reason that long-term bonds, such as couples, require higher cognitive resources, because longer ties involve keeping track of and managing the inevitable conflicts that arise regarding access to resources, parental investment, and time budget. To maintain such a relationship, individuals need skills to solve such conflicts, to influence others' behavior, to remember previous experiences, and make a plan to maximize their reproductive success. On the contrary, unstable relationships, such as those of multi-male groups, do not require these cognitive resources. They are not needed to recognize each other. Support for the hypothesis is found in a correlational analysis of different groups of animals in terms of relative brain size and style of social relationship (Fig. 3).

In fact, in previous work on ungulates, Shultz and Dunbar (2006) already suggested that the most favorable conditions for brain enlargement are: a highly social way of life, monogamous couplings, and the so-called "mixed environments" of neither closed nor unlimited habitats (Fig. 4). 
Figure 3.

Relative brain size according to parenting system in (a) carnivores, (b) ungulates, (c) bats, and (d) birds. Stable couples are more likely to be found in species with relatively bigger brains (Shultz andDunbar 2007, p. 2432).
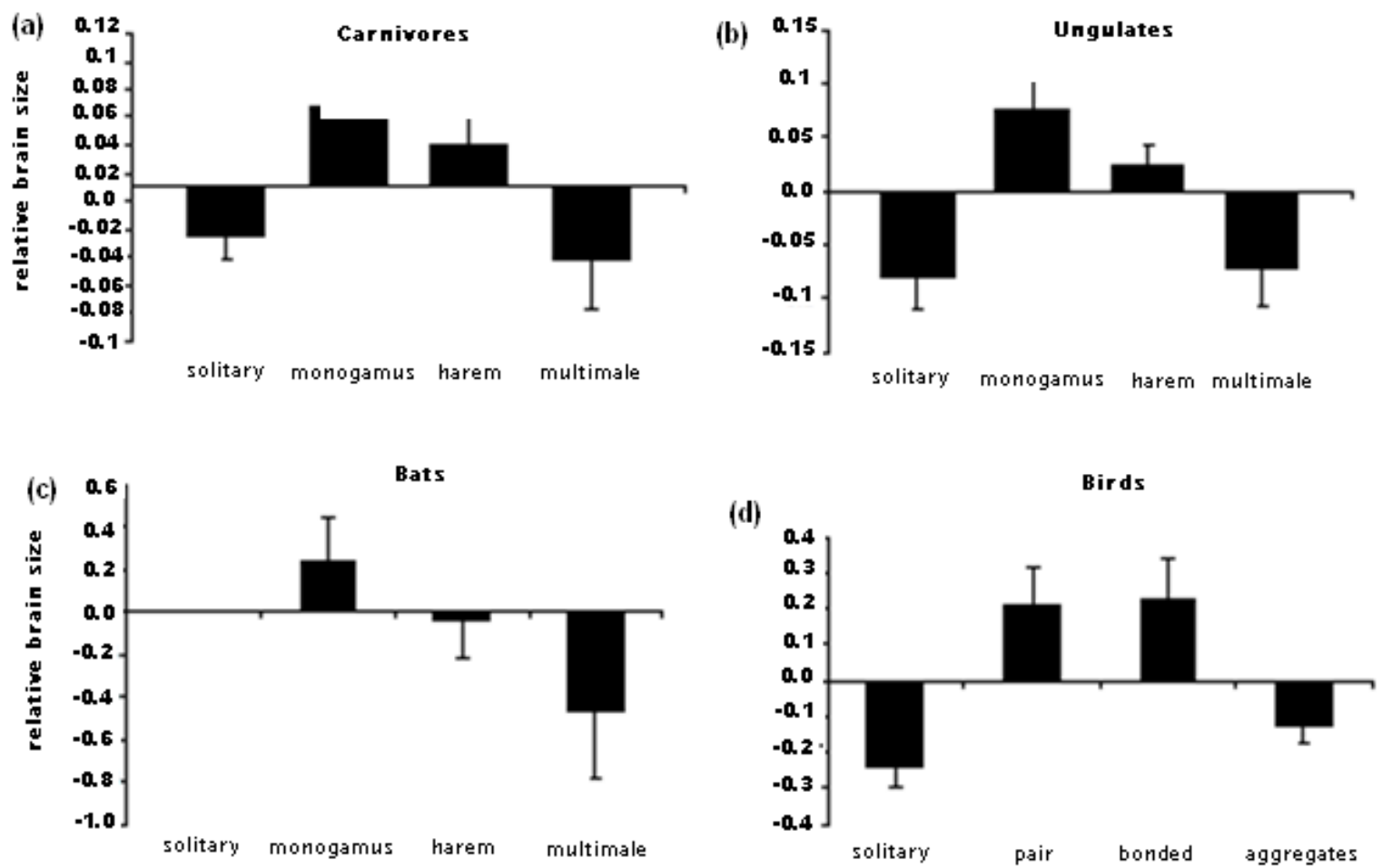

Social system

Figure 4.

Relation between relative neocortex size and social and ecological factors: (a) sociality, (b) mating strategy, and (c) habitat use (Shultz andDunbar 2006, p. 212).
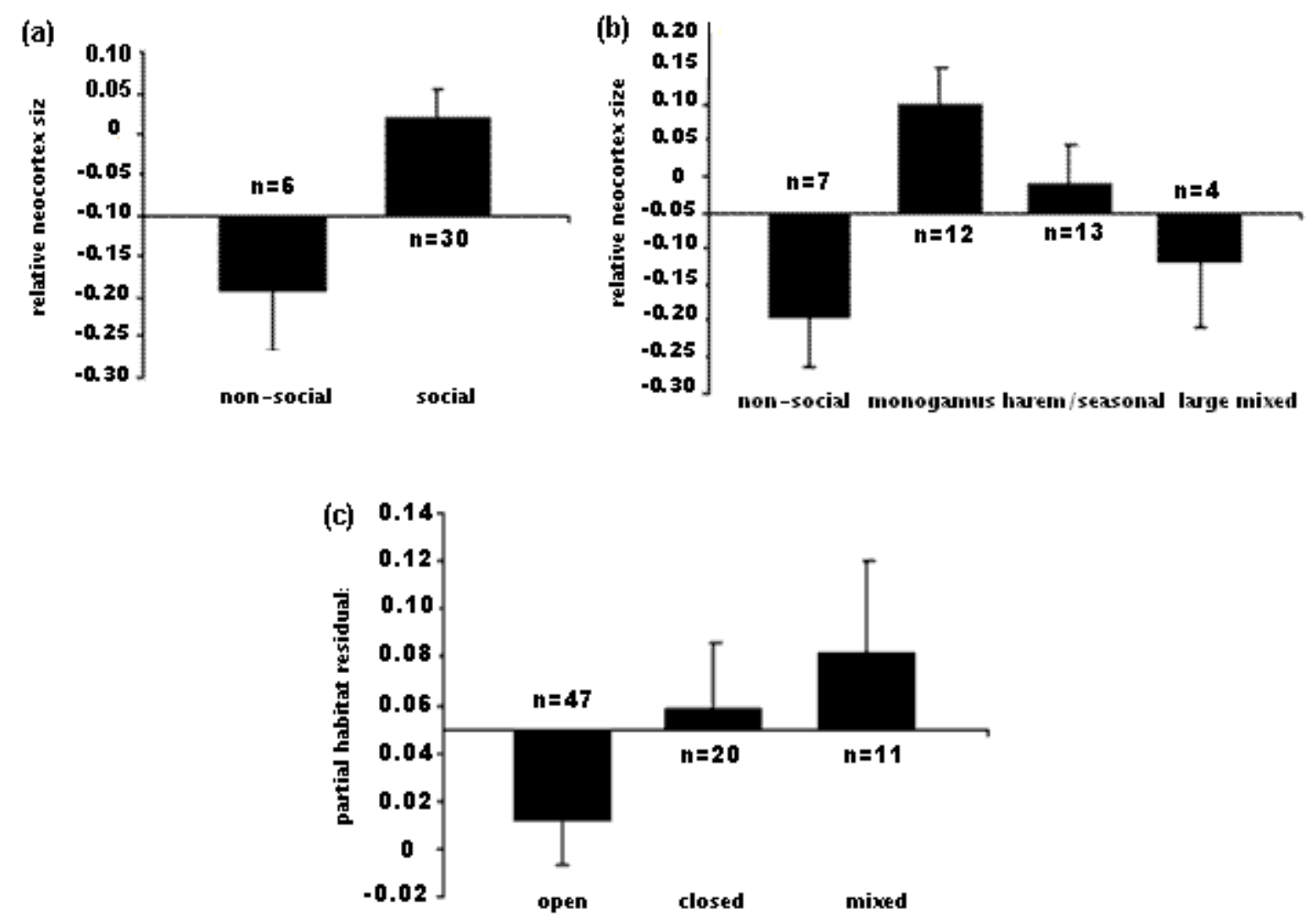
Nevertheless, primates are different. In contrast to other taxa, primates show a clear correlation between group size and relative brain size (specifically, neocortex ratio with respect to body size). Indeed, this is the most important correlation, over and above other ones such as social system, mating strategy, or habitat use. Primates are also special because they show strong ties among individuals. In particular, anthropoid primates live in large social groups with stable relationships often based on matrilineal or patrilineal kinship, coalitions, and affiliative relationships established and maintained through grooming between individuals not genetically related. Primates establish intense and focused relationships with other group members. In other taxa, these relationships only exist between reproductive couples. Moreover, in contrast to other taxa, the harem and the multi-male social systems also correlate with larger relative cerebral sizes in primates (Shultz and Dunbar 2007) (Fig. 5).

Figure 5.

Relative brain size according to the social system in primates (Dunbar 2007, p. 2432).

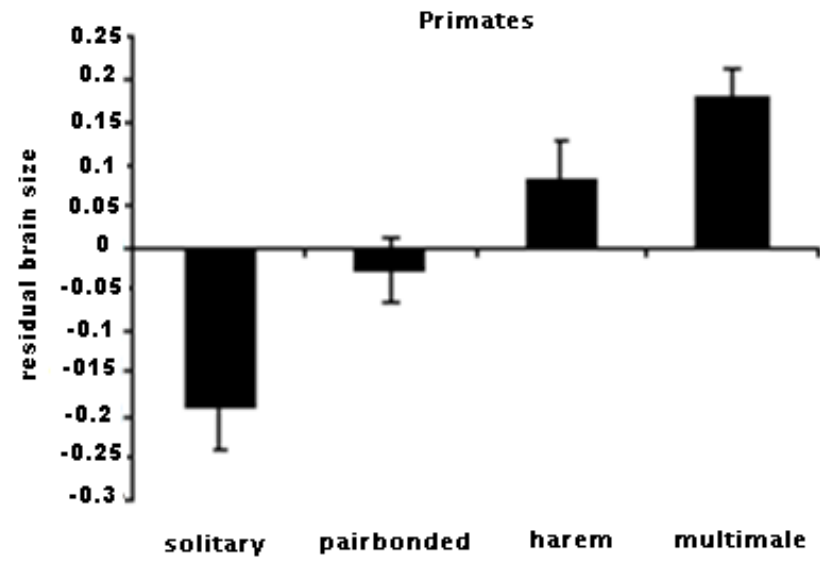

These findings suggest the relevance of the neocortex in sustaining primates' social life, as the SBH predicts. Croney and Newberry's (2007) results also support the SBH by suggesting that longer coexistence among the group members fosters cognitive development in order to be able to recognize other individuals, coordinate strategies of survival and domination, exchange and transmit information within the group, improve social attention, use deception tactics, manipulate and compete, and so on. This is also in line with Fletcher et al. (1995) who, using PET imaging, found higher activity in prefrontal areas when primates recognized and interpreted visual signs and emotional states in other individuals, as well as when identifying behaviors, manipulating and processing information. Likewise, Byrne (1995) also found that relative neocortex size correlates with frequency of tactical deception in primates.

Even more to the point, recent neuroimaging studies, such as that of Lewis et al. (2011), have found a positive correlation between volume of gray matter in the average prefrontal cortex and size of an individual's social network. A similar correlation appears again in a new analysis of Powell et al. (2012); in this case between the orbital volume of the prefrontal cortex and social group size. Nevertheless, whereas the neocortex is clearly involved in attentional and behavioral control, it is not the only brain area involved in social life; think of memory, for instance, which is related to tempo-parietal areas, or emotions, which involve the limbic system. Consequently, the evidence concerning relative neocortex size falls short when providing full support for the SBH because it fails to account for many other mental functions involved in social life.

Another line of research to support the SBH has been to test whether relative neocortex size in primates correlates more with the juvenile period (when social learning is central) than with gestation time (Dunbar 1998). Again, the evidence links neocortex and learning, but this might be due to brain immaturity at birth as a side-effect of the erect posture. In any case, evolution drove humans to develop their brains during a long process of social influence and learning, which distinguishes them from other species. Human ontogenesis is the key of the brain plasticity required to learn (Hutchinson et al. 2005).

In summary, we now see how the SBH has to be made more precise again. Once the kind of social relationships is taken into account, as well as the different cognitive skills required to sustain them, relative neocortex size cannot be the whole story. More importantly, attention to social learning and brain plasticity during ontogenesis involves realizing that they play a role in fostering cultural diversity, just as in adapting to it. The SBH tries to address this problem by looking for social universals originating in a primitive social structure and attempts to generalize it.

\section{UNIVERSAL CONSTRAINTS IN HUMAN SOCIAL LIFE}

From the initial connection between brain and sociality, Dunbar is driven to consider the question of universal constraints in humans' social life. Such constraints are conceived by Dunbar in terms of the time required and the limited cognitive resources available to establish and maintain the different types of human social relationships. While socio-economic and marital status, age, education, or the family configuration are factors known to influence the creation and structure of social networks (McPherson, SmithLovin and Brashears 2006), Dunbar and colleagues suggest the following:

\section{Number and type of relationships}

The first of these constraints is the famous Dunbar's number (Dunbar 1993), which indicates the maximum number of social relationships 
humans can keep: approximately 150 . This number comes from the observation of different human groups that maintained stable relations over history, in addition to extrapolation from relative neocortex size to group size in different species. Similarly, Hill and Dunbar (2003) suggested a limit to the number of relations established by universal cognitive constraints derived from the human way of maintaining social cohesion, which requires face-to-face interaction and individualized pursuit. Nevertheless, Dunbar finally realizes that what matters is not the number per se but the type of relationships.

In this regard, Roberts et al. (2009) found a general pattern in the structure of human social networks in contemporary societies. They identified three circles of social relationships: i) the "support clique", which consists of around 5 emotionally close individuals who receive and provide help or advice in difficult times; ii) the "sympathy group", which is a group of friends with at least a monthly contact and includes an average of 12 to 15 people; and iii) the rest of individuals with whom one keeps sporadic contact. Accordingly, Roberts et al. (2009) view the most sporadic relationships as a form of social capital, as an investment in social relationships from which a future benefit is expected (Lin 1999). These types of relationships imply different levels of emotionality (Roberts and Dunbar 2010), which determine different costs of maintenance, in terms of both time and mental resources. In addition to the former groups, they also identify groups of between 30 and 50 individuals (bands), those of 500 individuals (mega-bands), and groups of between 1,000 and 2,000 members (tribes). Again, these different group sizes are supposed to be universal patterns across human social diversity, which are supposedly derived from, and constrained by, the initial hominin structure.

This approach, however, still overlooks the diversity of human societies. On the one hand, participants in the studies in support of these supposed universal group sizes (Roberts et al. 2008; Roberts et al. 2009; Roberts and Dunbar 2010) all belong to a cultural and socio-economic sample highly restricted to economically developed European countries (UK students, Belgian participants, or English residents of a rural community). On the other hand, it is still guided by the search for fixed numbers at each level. But what if a group of 100 members is found? In fact, the extensive families of traditional societies have no place in Dunbar's typology. Even more, it is assumed that each group size encompasses several groups one degree below, but again, without proper justification.

These possibilities cannot be excluded, particularly if the theory contends to apply to current societies. Nowadays, humans live in broader societies, and many researchers analyze the current globaliza- tion phenomenon and the new social configurations it gives rise to. Therefore, a better way to look for universals in social structure is to try to understand the cognitive resources and emotional motivations for social life, and how they give rise, in different ecological contexts, to different social relations and structures. From this point of view, Dunbar's number and his view of universal social circles of a fixed size (Roberts et al. 2009) miss the point. A more solid ground in the search for social universals can be found in the basic human need for affiliation and our prosocial motivations. The idea is that effective social configuration is structured around small groups of closely attached individuals whose number depends on cognitive and time resources, but which can vary depending on the ecological pressures.

\section{Cognitive and time requirements to maintain social relationships}

Maintaining each type of social bond demands different cognitive requisites and time investment. Close ties are those that involve emotional charge, but they can be of different types. According to Roberts et al. (2009), ties with relatives demand less dedication in terms of time than other relationships because of the combination of the obligation to help kin and their high level of structural embeddedness. Non-kin close bonds, however, imply more dedication to maintain the relationship through frequent communication in real-time by phone or especially face-toface (Mok, Wellman and Basu 2007; Utz 2007). The longer time required to create and maintain these ties limits their number, thus establishing an upper limit of non-kin close ties. Accordingly, the other relationships are weaker and less emotionally close, and therefore also need less personal dedication. As a result, this latter kind of relationship can be maintained with a greater number of individuals due the smaller time investment required.

For humans and primates, Zhou et al. (2005) also established a fixed numerical sequence in the social relationship types of between 3 to 5 relationships (support group), 9 to 15 (sympathy group), and 30 to 50 individuals (typical bands of huntersgatherers that are more unstable but a part of the 150 group members). This sequence coincides with a stable scale of around 3, which increases geometrically and is thought to be universal. According to Dunbar, this sequence in the hierarchy of social closeness is related to the above-mentioned cognitive limitations because when such limitations are exceeded, the stability of the relationships diminishes and the group divides. In the same sense, Stiller and Dunbar (2007) hypothesized which cognitive essentials limit in number the relationships of each kind supported simultaneously. Thus, they single out the theory of mind and memory as the key to the support group size due to the cognitive limitations 
it involves. Accordingly, the theory of mind fixes a cognitive limitation in the number of intentionality levels that humans can attribute to others ("John believes that Peter thinks that Mary wants that Frank...) (Kinderman, Dunbar and Bentall 1998). Stiller and Dunbar (2007) think that humans fail when attempting to retain more than 5 intentionality levels, and this number corresponds to the support group size. Similarly, short-term memory is limited to 5 (the current value of Miller's [1956] famous number $7+/-2$ ). Memory capacity is needed to retain information about these relationships (Barrett, Henzi and Dunbar 2003).

On the other hand, Roberts et al. (2008) also analyzed personality influences in social relationships, but they scarcely found any influence. They only found a small effect of extroversion in support groups, right at the time of creating new relationships, when individuals face different life circumstances, or change their place of residence. But they did not find any influence of neuroticism. Therefore, they concluded that it is the cognitive level that matters for social bonding.

Similarly, according to Dunbar (1993), language presumes a cognitive skill that is very closely rela- ted to social activity, which facilitates and multiplies social complexity and is parallel to neocortex development. Language serves as a substitute in humans to mutual grooming in primates, multiplying by 2.8 its possibilities of maintaining relationships over grooming. Cohen (1971) also found human cognitive limitations in language when he established a maximum number of 5 persons with whom it is possible to have a conversation at a normal voice level. This affirmation reinforces Dunbar's (1993) idea of cognitive limitations to maintaining cohesive groups. When this number is exceeded, the conversation groups divide because attention and listening capacities drop (Henzi et al. 2007).

Human conversations traits are analyzed to verify whether language origin was related to the creation of social bonds (Dunbar, Marriott and Duncan 1997). In this respect, Dunbar (1993) concluded that $60 \%$ of human conversations consist of social gossip. Similarly, other experiments on social information transmission have found that social gossip is transmitted more frequently than other social topics or any other issues (Mesoudi, Whiten and Dunbar 2006) (Fig. 6).

Figure 6.

Total number of propositions remembered in every transmission, independently of their precision (Mesoudi et al. 2006, p. 412).

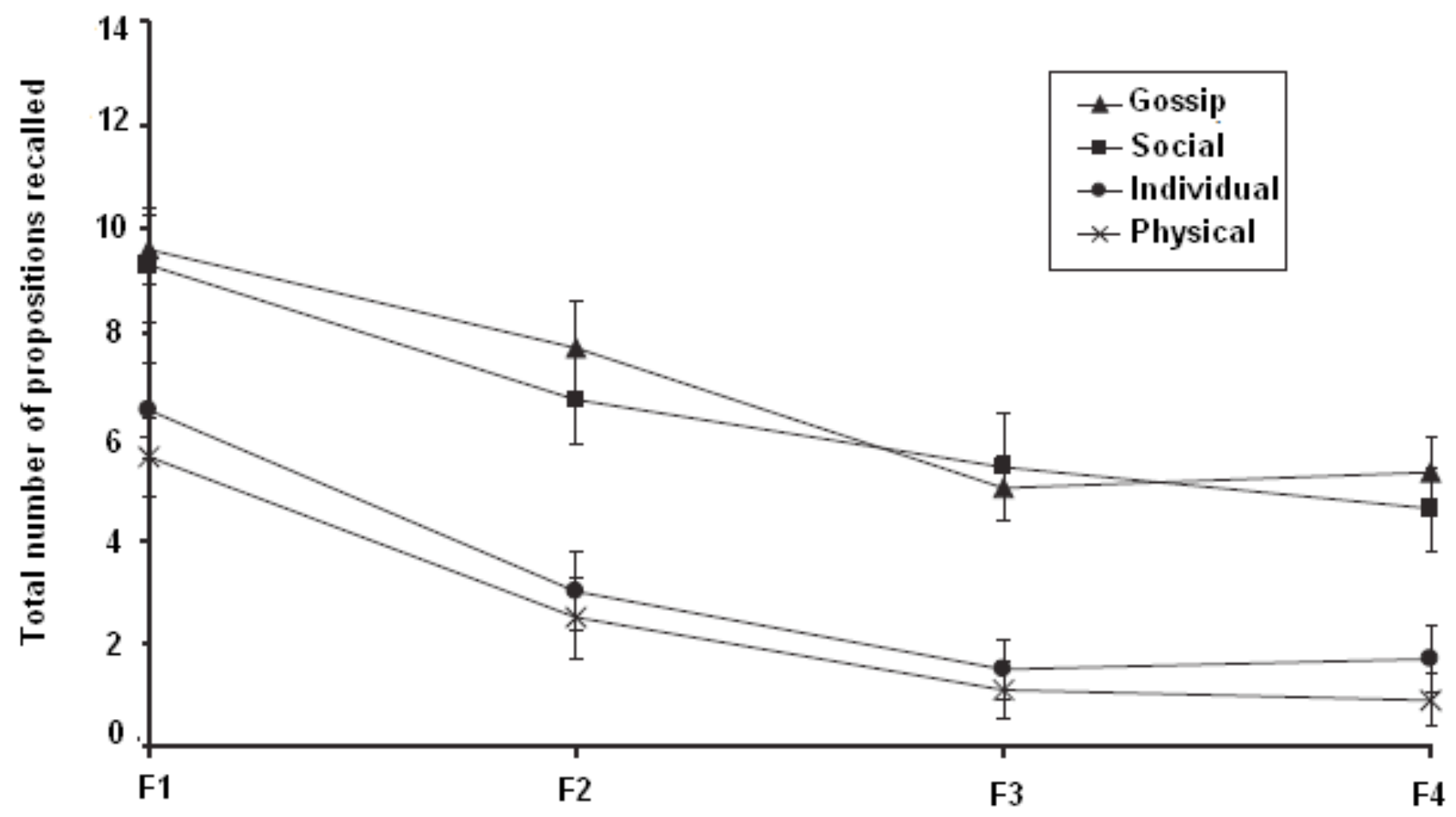

Generation 
Dunbar, Marriott, and Duncan (1997) also suggested that most informal conversations usually refer both to one's own personal issues and other people's and they are mere social activities. These studies provide support for the SBH by emphasizing social influence in a cognitive skill such as language, which, according to Dunbar (2009b), requires a sophisticated capacity for intentional attribution. Nevertheless, the previous gossip percentage constitutes a weak argument to extrapolate the social origin of human language, as it comes from a study based on a limited number of participants who live together in a very concrete social context. Another example of the simple linear relations is used by Dunbar to support the SBH. In fact, Freeberg, Dunbar, and Ord (2012) have recently begun to refer to the Social Complexity Hypothesis to explain the communication-to-language step in more complex social contexts. In a similar sense, Henzi et al. (2007) have tried to link meta-representational capacity with social group size. Nevertheless, all these arguments that attempt to identify cognitive mechanisms as possible limitations to certain social practices are insufficient to support the SBH on their own; they just provide circumstantial evidence.

Although Dunbar's classification of relationship types is interesting, he does not consider the next logical step: whether the structure of human social networks is also conditioned by basic human needs or by the social practices themselves. From this standpoint, an anthropological perspective on social practices and culture is in order to understand how social networks are configured by means of cultural resources as identities, symbology, beliefs, norms, and technology. Dunbar concentrates exclusively on interpersonal relationships, but the SBH should also consider other forms of social relationships (intra-group vs. inter-group, for example, or other social psychology phenomena) that involve the individual's identification with a generic group. This type of considerations leads us to view with some skepticism the recent line of development of the SBH regarding the influence of Internet on social relationships. Dunbar and collaborators have tried to demonstrate the same type of social groups in the new virtual social networks (Dunbar 2012b), but they must resort to analogies that overlook the different nature of virtual relationships.

In other words, a better way to develop Dunbar's program, in our view, requires attention to the human need for social bonding. It is this social motivation which is basic, universal, and drives humans to form social groups of a small size. Becoming an ultra-social species is not just a matter of group membership, but of affiliation. The key to understanding the evolution of our species is not so much that bigger brains allowed for bigger groups, but that a new pattern of attachment appeared, one dependent on cognitive resources and time investment, but which is emotional in nature. The basic "support group" seems to be enough to cover the most basic human needs for help, cooperation, affectivity, and safety, especially in difficult times. These bonds are reinforced by a stronger emotional load which, in turn, promotes greater involvement. Besides, the creation of broader and less emotional networks might serve another type of social needs that require lower implication, possibly for weaker relationships.

Both personal and general trust seems to play a key role in this respect (Acedo-Carmona and Gomila 2014). Dunbar seems to have realized the need to consider the role of trust in social cooperation (Sutcliffe et al. 2011). In a way, this amounts to an implicit recognition that his previous model was too simple. In the same sense, Dunbar (2012a) began to use other elements in his explanation of the SBH, such as the relevance of laughing and its relation to endorphins, as a possible useful mechanism to share social activity. Instead of a strict compartmentalization of kinds of groups, cognitive and temporal resources, and social relations as a way to finding universals in social and cognitive evolution, the suggested approach turns to the evolutionary appearance of a new form of social bonding as the trigger of the neural, cognitive, and social changes that followed.

\section{RECONSTRUCTION OF HUMAN PHYLOGENESIS}

Another goal of the SBH is to offer the grounds for a reconstruction of the hominization process. To this extent, it tries to interpolate the social characteristics of the fossil species of our hominin lineage from the consideration of living species, namely anthropoid monkeys and modern humans. The proposal has moved from a first phase grounded in group size and relative neocortex size - which, as we have already indicated repeatedly, turns out to be too simplisticto a more recent and complex proposal.

Thus, in a first attempt, Aiello and Dunbar (1993) used the relation between neocortex volume and group size. They estimated the neocortex volume of different fossil species from their cranial volume using the scale identified by Finlay and Darlington (1995). From the estimation of neocortical volumes, they inferred the group size of these species, assuming that the correlation initially found between both parameters held as well. As a result, Homo erectus was singled out as the beginning of the key transition towards the greater increase of cerebral volume and group size with respect to the great apes (Fig.7).

From previous estimations of group size of different species, they inferred the time spent on social activities needed to maintain group cohesion. Assuming that individuals cannot dedicate more than $30 \%$ of their daily time to social activity and still have time to attend to the rest of their needs (this percentage might change if more selective pressures are considered), they calculated the maximum number of individuals that can interact. Thus, knowing the group 
size of different fossil species and the maximum percentage of time to social dedication, they calculated the time when language appeared. They concluded that language appeared 0.5 million years ago. This period coincides with appearance of archaic humans; hence, the Neanderthal might already have possessed a social speech, according to Dunbar (2003).

In a new reconsideration of the question, Dunbar (2003) inferred that only modern humans and Neanderthals are capable of the level 4 of intentionality (Fig. 8), comparing intentionality levels of "catarrhine primates" and their cranial volume. Level 4 is especially important because, supposedly, it is needed for religion or the appearance of symbolic culture. This estimation coincides with the available archaeological evidence that places language appearance with the archaic Homo sapiens.

Nevertheless, basing the whole explanation of the hominin evolutionary process on a simplified and not entirely validated hypothesis involves some risks that imply the very weakness of its conclusions. Although fossils reveal the relation between cerebral growth and superior cognitive complexity, due to the tech- nical changes in material culture, the $\mathrm{SBH}$ is not the only possible hypothesis to account for it.

Recently, Shultz, Nelson, and Dunbar (2012), after admitting that group size is not enough to explain hominids' brain evolution, tested their previous works and tried to add other factors to their statistical analysis. They added elements such as climate, predatory pressures, sociality, and language evolution. The analysis again attempted to reject the $\mathrm{EH}$ in favor of the $\mathrm{SBH}$, although seeking a slightly more complex social explanation. They concluded that different forces operate in the brain evolutionary process, with periods of gradual cerebral growth and moments of prominent evolutionary jumps which coincide neither with important climate changes nor in Africa and Europe. Undoubtedly, they admit that group size could hardly depend on just one variable, and ecological factors (available resources, competition level, climate, etc.), interactive factors (fertility, sexual ratio, etc.), or even social factors (language or norms on reproduction and familiar organization) might have something to do with this. But the coherent thing to do, after this acknowledgement, would be to drop the attempt to find a linear relation in this regard.

Figure 7.

Social group size predicted for populations of hominids, including modern humans, using the regression equation for the group size on the neocortex ratio (Dunbar, 2003, p. 173).

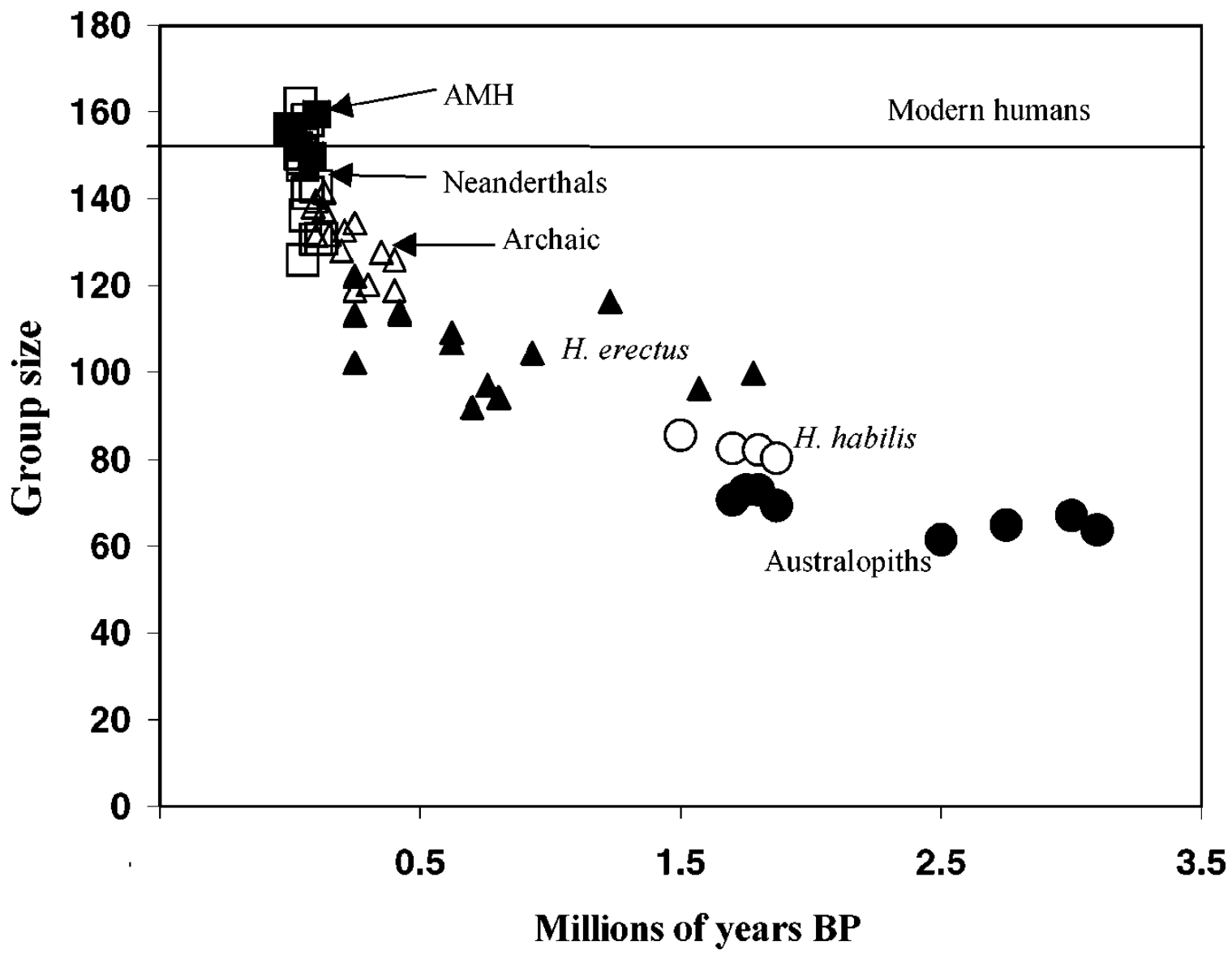

RS [online] 2016, 74 (3), e037. REVISTA INTERNACIONAL DE SOCIOLOGÍA. ISSN-L: 0034-9712 
Figure 8.

Level of attainable intentionality (or theory of the advanced mind) for hominines populations respect to time (Dunbar 2003, p. 178).

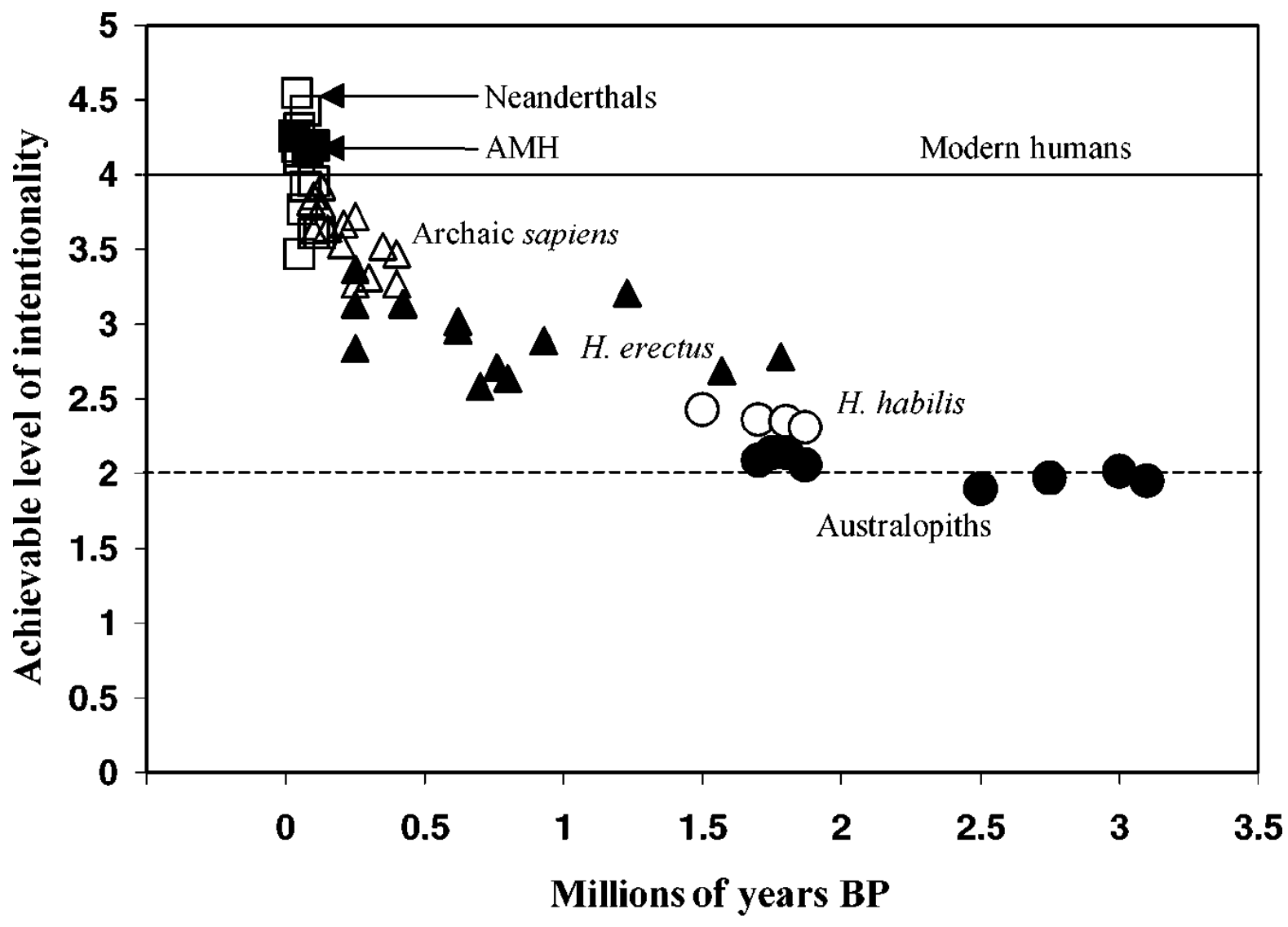

\section{Conclusion}

the $\mathrm{SBH}$ faces a paradoxical situation. On the one hand, very little remains of the original formulation in terms of the relative proportion of neocortex and group size (as Dunbar acknowledged in 2007). On the other hand, much of the evidence amassed over the years is still valid, but some of the claims derived from it turn out to be too simplistic. However, the $\mathrm{SBH}$ still seems to be a program that is on the way to providing a satisfactory account of human social and psychological evolution.

Certainly, Dunbar seems to be well aware of this situation. His more recent papers acknowledge this complexity and go beyond the search for simple linear correlations. Thus, for example, neurobiological analyses of brain areas involved in certain social aptitudes (Lewis et al. 2011; Dunbar 2010) are carried out, just as reviews of their neurochemical bases (Machin and Dunbar 2011). Similarly, he is also interested in the topology of social networks, and not just in group size (Dunbar and Shultz 2007). This confirms the simplicity of the previous versions of the theory based merely on neocortex size. Nevertheless, adding complexity to the SBH formulation entails calling into question some of its core assumptions, such as the relevance attributed to relative neocortex size over other cerebral structures, as the psychological capacities involved in human sociality do not depend exclusively on the neocortex. Likewise, having displaced the focus from group size to social relationships and their network structure, the pursuit of "magic numbers" (5-15-50-150) in effective social configurations overlooks the vast diversity of human social life. Universals are not to be found in such simple group sizes, but in the motivation to form robust social bonds.

Similarly, Dunbar has become aware of the need to go beyond correlational analysis because complex networks give rise to non-linear patterns. Thus, Dunbar has begun to resort to network analysis and to pay attention to trust networks. In this sense, Dávid-Barrett and Dunbar (2012), Dunbar (2012b), and Curry and Dunbar (2011) exemplify the interest of social network analysis, even if still in the service of finding "group constants". The analysis of trust networks, however, is instrumental to better understand group cohesion (Acedo-Carmona and Gomila 2014).

Moreover, although the SBH provides interesting elements on which to go on working, it becomes finally unsatisfactory because it does not contemplate that 
its functionalist explanation of the increase in relative brain size (achieving a selective advantage from living in larger groups) needs to be supplemented with a causal explanation of how this happened. In other words, the adaptive solution of the hominin lineage remains incomplete: in a similar situation, many species chose adaptive routes other than increased brain size. But this point is not yet acknowledged, the functional explanation is viewed as sufficient: "large brains have arisen over evolutionary time as a response to the social and ecological conflicts inherent in group living" (Shultz and Dunbar 2007) or: "primates evolved large brains to manage their unusually complex social systems" (Dunbar 2009a). These statements do not consider other highly social species that have not developed such cerebral and cognitive levels of development. In other words, even when the route of greater telencephalization could have been beneficial for many other species, they did not follow it. There are species that support severe environmental pressures and must travel long distances to get food, such as ungulates, but such pressures did not force them to create more complex social systems to face these environmental challenges, ensure reproduction, or even protect their offspring.

\section{References}

Acedo-Carmona, C. and Gomila, A. 2014. "Personal trust increases cooperation beyond general trust". PloS ONE 9(8): e105559. http://dx.doi.org/10.1371/journal. pone.0105559

Aiello, L. and Dunbar, R. 1993. "Neocortex size, group size and the evolution of language". Current Anthropology 34: 184-193. http://dx.doi.org/10.1086/204160

Barrett, L., Henzi, P. and Dunbar, R.I.M. 2003. "Primate cognition: from 'what now?' to 'what if?'”. Trends in Cognitive Sciences 7, 11: 494-497. http://dx.doi.org/10.1016/j. tics.2003.09.005

Byrne, R.W. 1995. The Thinking Ape. Oxford: Oxford University Press.

Byrne, R.W. and Whiten, A. 1988. Machiavellian intelligence. Oxford: Oxford University Press.

Cohen, J.E. 1971. Casual groups of monkeys and men. Cambridge: Harvard University Press. http://dx.doi. org/10.4159/harvard.9780674430556

Croney, C.C. and Newberry, R.C. 2007. "Group size and cognitive processes". Applied Animal Behavior Science 103: 215-228. http://dx.doi.org/10.1016/j.applanim.2006.05.023

Curry, O. and Dunbar, R.I.M. 2011. "Altruism in networks: the effect of connections". Biology Letters 7, 5: 651-653. http://dx.doi.org/10.1098/rsbl.2010.1202

Dávid-Barrett, T. and Dunbar, R.I.M. 2012. "Cooperation, behavioural synchrony and status in social networks". Journal of Theoretical Biology 308: 88-95. http://dx.doi. org/10.1016/j.jtbi.2012.05.007

Dunbar, R.I.M. 1988. Primate Social Systems. London: Chapman \& Hall. http://dx.doi.org/10.1007/978-14684-6694-2

Dunbar, R.I.M. 1991. "Functional significance of social grooming in primates". Folia Primatologica 57: 121-131. http://dx.doi.org/10.1159/000156574
In summary, from the analysis and review of Dunbar's works, we can conclude that, although the $\mathrm{SBH}$ does not remain robustly established, its works on the evolution of human sociality and the cognitive mechanisms that made it possible open an interesting route to be explored more thoroughly. In particular, closely examining small-scale human societies to compare them with large current human agglomerations is a timely goal for research in order to carry Dunbar's program further. In other words, just as Dunbar tried to find evolutionary footprints in current social relationships, it would be equally interesting to determine whether there are social networks working as small-scale societies inside current complex societies, or whether social cohesion in both societies depends on a similar human motivation for social bonding.

\section{AcknOWLedgements}

This research was funded by the Research Projects FFI2010-20759 and FFI2013-44007-P (Spanish Ministry of Science and Innovation). Cristina Acedo Carmona was supported by a Ph.D. fellowship from the Spanish Ministry of Education (AP2009-3369).

Dunbar R.I.M. 1992. "Neocortex size as a constraint on group size in primates". Journal of Human Evolution 20: 469493. http://dx.doi.org/10.1016/0047-2484(92)90081-J

Dunbar, R.I.M. 1993. "Co-evolution of neocortex size, group size and language in humans". Behavioral and Brain Sciences 16, 4: 681-735. http://dx.doi.org/10.1017/ S0140525X00032325

Dunbar, R.I.M. 1995. "Neocortex size and group size in primates: a test of the hypothesis". Journal of Human Evolution 28: 287-296. http://dx.doi.org/10.1006/ jhev.1995.1021

Dunbar, R.I.M., Marriott, A. and Duncan, N.D.C. 1997. "Human conversational behaviour". Human Nature 8, 3: 231246. http://dx.doi.org/10.1007/BF02912493

Dunbar, R.I.M. 1998. "The social brain hypothesis". Evolutionary Anthropology 6, 5: 178-190. http://dx.doi. org/10.1002/(SICI)1520-6505(1998)6:5<178::AIDEVAN5>3.0.CO;2-8 / http://dx.doi.org/10.1002/ ( SICI) $1520-6505$ (1998)6:5<178:: AID EVAN5>3.3.CO;2-P

Dunbar, R.I.M. 2003. "The social brain: mind, language, and society in evolutionary perspective". Annual Review of Anthropology 32:163-181. http://dx.doi.org/10.1146/ annurev.anthro.32.061002.093158

Dunbar, R.I.M. and Shultz, S. 2007a. "Evolution in the social brain". Science 317: 1344-1347. http://dx.doi. org/10.1126/science. 1145463

Dunbar, R.I.M. and Shultz, S. 2007b. "Understanding primate brain evolution". Philosophical Transactions of the Royal Society B 362: 649-658. http://dx.doi. org/10.1098/rstb.2006.2001

Dunbar, R.I.M. 2009a. "The social brain hypothesis and its implications for social evolution". Annals of Human Biology 36, 5: 562-572. http://dx.doi. org/10.1080/03014460902960289 
Dunbar, R.I.M. 2009b. "Why only humans have language". Pp. 12-35 in The Prehistory of Language. 1st ed. New York: Oxford University Press. http://dx.doi.org/10.1093/acpr of:oso/9780199545872.003.0002

Dunbar, R.I.M. 2010. "The social role of touch in humans and primates: behavioural function and neurobiological mechanisms". Neuroscience and Biobehavioral Reviews 34: 260-268. http://dx.doi.org/10.1016/j.neubiorev.2008.07.001

Dunbar, R.I.M. 2012a. "Bridging the bonding gap: the transition from primates to humans". Philosophical Transactions of the Royal Society B 367: 1837-1846. http://dx.doi. org/10.1098/rstb.2011.0217

Dunbar, R.I.M. 2012b. "Social cognition on the Internet: testing constraints on social network size". Philosophical Transactions of the Royal Society B 367: 2192-2201. http://dx.doi.org/10.1098/rstb.2012.0121

Finlay, B.L. and Darlington, R.B. 1995. "Linked regularities in the development and evolution of mammalian brains". Science 268: 1578-1584. http://dx.doi.org/10.1126/ science. 7777856

Fletcher, P., Happé, F., Frith, U., Baker, S.C., Dolan, R.J., Frakowiak, R.S.J. and Frith, C.D. 1995. "Other minds in the brain: a functional imaging study of "theory of mind" in story comprehension". Cognition 57, 2: 109128. http://dx.doi.org/10.1016/0010-0277(95)00692-R

Freeberg, T.M., Dunbar, R.I.M. and Ord, T.J. 2012. "Social complexity as a proximate and ultimate factor in communicative complexity". Philosophical Transactions of the Royal Society B 367: 1785-1801. http://dx.doi. org/10.1098/rstb.2011.0213

Henzi, S.P., de Sousa Pereira, L.F., Hawker-Bond, D., Stiller, J., Dunbar, R.I.M. and Barrett, L. 2007. "Look who's talking: developmental trends in the size of conversational cliques". Evolution and Human Behavior 28: 66-74. http://dx.doi.org/10.1016/j.evolhumbehav.2006.07.002

Hill, R.A. and Dunbar, R.I.M. 1998. "An evaluation of the roles of predation rate and predation risk as selective pressures on primate grouping behaviour". Behaviour 135: 411430. http://dx.doi.org/10.1163/156853998793066195

Hill, R.A. and Dunbar, R.I.M. 2003. "Social network size in humans". Human Nature 14, 1: 53-72. http://dx.doi. org/10.1007/s12110-003-1016-y

Humphrey, N.K. 1976. "The social function of intellect". Pp. 303- 317 in Growing Points in Ethology. 1st ed. Cambridge: Cambridge University Press.

Hutchinson, S., Hui-Lin Lee, L., Gaab, N. and Schlaug, G. 2003. "Cerebellar volume of musicians". Cerebral Cortex 13, 9: 943-949. http://dx.doi.org/10.1093/cercor/13.9.943

Kinderman, P., Dunbar, R., Bentall, R.P. 1998. "Theoryof-mind deficits and causal attributions". British Journal of Psychology 89: 191-204. http://dx.doi. org/10.1111/j.2044-8295.1998.tb02680.x

Kudo, H. and Dunbar, R.I.M. 2001. "Neocortex size and social network size in primates". Animal Behaviour 62: 711722. http://dx.doi.org/10.1006/anbe.2001.1808

Lehmann, J., Korstjens, A.H. and Dunbar, R.I.M. 2007. "Group size, grooming and social cohesion in primates". Animal Behaviour 74: 1617-1629. http://dx.doi. org/10.1016/j.anbehav.2006.10.025

Lewis, P.A., Rezaie, R., Brown, R., Roberts, N. and Dunbar, R.I.M. 2011. "Ventromedial prefrontal volume predicts understanding of others and social network size". Neuroimage 57: 1624-1629. http://dx.doi.org/10.1016/j. neuroimage.2011.05.030

Lin, N. 1999. "Building a network theory of social capital". Connections 22: 153-159
Machin, A.J. and Dunbar, R.I.M. 2011. "The brain opioid theory of social attachment: a review of the evidence". Behaviour 148, 9-10: 985-1025.

McNab, B.K. and Eisenberg, J.F. 1989. "Brain size and its relation to the rate of metabolism in mammals". American Naturalist 133:157-167. http://dx.doi.org/10.1086/284907

McPherson, M., Smith-Lovin, L., Brashears, M.E. 2006. "Social isolation in America: changes in core discussion networks overtwo decades". American Sociological Review71:353375. http://dx.doi.org/10.1177/000312240607100301

Mesoudi, A., Whiten, A. and Dunbar, R.I.M. 2006. "A bias for social information in human cultural transmission". British Journal of Psychology 97: 405-423. http:// dx.doi.org/10.1348/000712605X85871

Miller, G.A. 1956 "The magical number seven, plus or minus two: some limits on our capacity for processing information". Psychological Review 63: 81-97. http://dx.doi. org/10.1037/h0043158

Mok, D., Wellman, B., Basu, R. 2007. "Did distance matter before the Internet? Interpersonal contact and support in the 1970s". Social Networks 29: 430-461. http://dx.doi. org/10.1016/j.socnet.2007.01.009

Moll, H. and Tomasello, M. 2007. "Cooperation and human cognition: the Vygotskian intelligence hypothesis". Philosophical Transactions of the Royal Society B 362: 639-648. http://dx.doi.org/10.1098/rstb.2006.2000

Powell, J., Lewie, P.A., Roberts, N., García-Fi-ana, M. and Dunbar, R.I.M. 2012. "Orbital prefrontal cortex volume predicts social network size: an imaging study of individual differences in humans". Proceedings of the Royal Society B 279, 1736: 2157-2162. http://dx.doi.org/10.1098/rspb.2011.2574

Roberts, S.G.B., Wilson, R., Fedurek, P. and Dunbar, R.I.M. 2008. "Individual differences and personal social network size and structure". Personality and Individual Differences 44: 954-964. http://dx.doi.org/10.1016/j. paid.2007.10.033

Roberts, S.G.B., Dunbar, R.I.M., Pollet, T.V. and Kuppens, T. 2009. "Exploring variation in active network size: Constraints and ego characteristics". Social Networks 31: 138-146. http://dx.doi.org/10.1016/j.socnet.2008.12.002

Roberts, S.G.B. and Dunbar, R.I.M. 2010. "The costs of family and friends: an 18-month longitudinal study of relationship maintenance and decay". Evolution and Human Behavior 32: 186-197. http://dx.doi.org/10.1016/j.evolhumbehav.2010.08.005

Shultz, S. and Dunbar, R.I.M. 2006. "Both social and ecological factors predict ungulate brain size". Proceedings of the Royal Society B 22, 273, 1583: 207-215. http:// dx.doi.org/10.1098/rspb.2005.3283

Shultz, S. and Dunbar, R.I.M. 2007. "The evolution of the social brain: anthropoid primates contrast with other vertebrates". Proceedings of the Royal Society B 274: 2429-2436. http://dx.doi.org/10.1098/rspb.2007.0693

Shultz, S., Nelson, E. and Dunbar, R.I.M. 2012. "Hominin cognitive evolution: identifying patterns and processes in the fossil and archaeological record." Philosophical Transactions of the Royal Society B 367: 2130-2140. http://dx.doi.org/10.1098/rstb.2012.0115

Stiller, J. and Dunbar, R.I.M. 2007. "Perspective-taking and memory capacity predict social network size". Social Networks 29: 93-104. http://dx.doi.org/10.1016/j.socnet.2006.04.001

Sutcliffe, A., Dunbar, R.I.M., Binder, J. and Arrow, H. 2011. "Relationships and the social brain: integrating psychological and evolutionary perspectives". British Journal of Psychology 103: 149-168. http://dx.doi.org/10.1111/ j.2044-8295.2011.02061.x 
Utz, S. 2007. "Media use in long-distance friendships". Information, Communication and Society 10: 694-713. http://dx.doi.org/10.1080/13691180701658046

Van Schaik, C.P. 1983. "Why are diurnal primates living in groups?" Behaviour 87:120-144. http://dx.doi. org/10.1163/156853983X00147

CRISTINA ACEDO CARMONA. PhD in Human Cognition and Evolution, B.A. in Social and Cultural Anthropology, and B.Sc. in Economics and Business Administration. Her research line is related to the evolution of human sociality, in particular, the evolution of cooperation and trust. She has been interested in the multidisciplinary analysis of trust and cooperation relationships within groups and in different cultures, using experimental games, group networks, ego networks and performing field work. She has published in journals such as Annals of the New York Academy of Sciences, PLoS ONE, Frontiers in Psychology and Behavioral and Brain Sciences. Her last article is "Deciding to cooperate: testing evolutionary constraints across cultural diversity in northern Ghana" (The Spanish Journal of Psychology, 2015, 18, e91, 1-16).
Zhou, W.X., Sornette, D., Hill, R.A. and Dunbar, R.I.M. 2005. "Discrete hierarchical organization of social group sizes". Proceedings of the Royal Society B 272: 439444. http://dx.doi.org/10.1098/rspb.2004.2970

ANTONI GOMILA BENEJAM. PhD in Philosophy, Full Professor of Psychology, and Director of the Master's Programme in Human Cognition and Evolution, at the University of the Balearic Islands. Has worked on the evolution of human cognition, particularly the evolution of the marks of the human mind: language, morality and aesthetic appreciation, as a result of the ultrasocial strategy of our species. He's become interested in the application of complex networks and evolutionary games theory to social sciences. His last book is Verbal Minds: language and the architecture of the mind (Elsevier, 2012). 